\title{
Preparation and in vivo Evaluation of a Sildenafil Lactate-loaded Solid Self-emulsifying Drug Delivery System
}

\author{
Si-Young Jung ${ }^{1,2}$, Dong Wuk Kim³ ${ }^{3}$ Dong Won Lee', Jong Soo Woo $^{2}$, Jong Oh Kim¹, \\ Chul Soon Yong ${ }^{1 \dagger}$ and Han-Gon $\mathrm{Choi}^{3 \dagger}$ \\ ${ }^{1}$ College of Pharmacy, Yeungnam University, 214-1, Dae-Dong, Gyongsan 712-749, South Korea \\ ${ }^{2}$ Pharmaceutical Research Center, Hanmi Pharm. Co., Paltan-myeon, 893-5 Hwaseong, Gyeonggi-Do 445-913, South Korea \\ ${ }^{3}$ College of Pharmacy, Hanyang University, 1271, Sa-3-Dong, Ansan 426-791, South Korea
}

(Received July 19, 2011 · Accepted August 10, 2011)

\begin{abstract}
To develop a sildenafil lactate-loaded solid self-emulsifying drug delivery system (SEDDS) with a fast onset of action and immediate action of erection, sildenafil lactate $(0.3 \mathrm{~g})$, which was prepared using a spray dryer, was dissolved in $4.7 \mathrm{~g}$ of the mixture of glyceryl monooleate/Transcutol/ Tween 20 (3/0.5/1, g). Its emulsion droplet size and pharmacokinetics in rabbits were evaluated compared with sildenafil citrate-loaded commercial tablet. The sildenafil lactateloaded SEDDS showed an emulsion droplet size of about $300 \mathrm{~nm}$. In pharmacokinetics study, it gave significantly faster $\mathrm{T}_{\max }$ than did the commercial tablet. Thus, the sildenafil lactate-loaded SEDDS at the one-third drug dose compared to sildenafil citrate-loaded conventional tablet might induce a fast onset of action and immediate erection without enhanced bioavailability compared with the sildenafil citrate-loaded commercial tablet.
\end{abstract}

Key words - Sildenafil lactate, SEDDS, Immediate erection, Pharmacokinetics

Sildenafil (1-[[3-(6,7-dihydro-1-methyl-7-oxo-3-propyl-1Hpyrazolo[4,3-d]pyrimidin-5-yl)-4-ethoxyphenyl]sulfonyl]-4methylpiperazine) is used to treat male erectile dysfunction. It is a selective inhibitor of cyclic guanosine monophosphate (cGMP)-specific phosphodiesterase type 5 (PDE5) (Boolell et al., 1996). However, this drug has low aqueous solubility and high membrane permeability, and is included in class 2 of the Biopharmaceutical Drug Classification system (Amidon et al., 1995). Its bioavailability is relatively low after oral administration since it is practically insoluble in water (Elshafeey et al., 2009; Wang et al., 2008). Thus, a commercial product has been developed with a salt form such as sildenafil citrate, which improves the drug's solubility. This commercial product (Viagra ${ }^{\circledR}$; Pfizer) is a tablet form containing sildenafil citrate equivalent to doses of 25,50 and $100 \mathrm{mg}$ of sildenafil base. It is rapidly absorbed after oral administration but gives a relatively low absolute bioavailability of about $40 \%$ (Nichols et al., 2002). However, its onset of action is relatively late, taking over 60 minutes in the presence of sexual stimulation (Eardly et al., 2002). Thus, a novel commercial product with a fast onset of drug effect and immediate erection must be needed.

In recent years much attention has been focused on lipid-

Co-corresponding Author:

Tel : +82-31-400-5802, E-mail : hangon@hanyang.ac.kr

Tel : +82-53-810-2812, E-mail : csyong@yumail.ac.kr

DOI : 10.4333/KPS.2011.41.4.249 microemulsion formulation with particular emphasis on self emulsifying or self-micro emulsifying drug delivery systems (SEDDS) to improve oral bioavailability of poorly water-soluble drugs (Balakrishnan et al., 2009). The clinical usefulness of the SEDDS are comprised of mixture of drug, oil, surfactants and/or cosolvents which form fine oil in water and/or water in oil emulsions upon dilution with aqueous medium or in vivo administration. Factors controlling the in vivo performance of SEDDS include their ability to form small droplets of oil and the polarity of the oil droplets to promote faster drug release into aqueous phase (Shah et al., 1994). The smaller oil droplets provide a large interfacial area for pancreatic lipase to hydrolyze triglycerides and thereby promote the rapid release of the drug and/or formation of mixed micelles of the bile salts containing the drug.

In this study, to develop a sildenafil lactate-loaded solid selfemulsifying drug delivery system (SEDDS) with a fast onset of action and immediate action of erection, it was prepared with sildenafil lactate, a salt form of sildenafil with improved solubility and bioavailability of poorly water-soluble sildenafil (Jung et al., 2011). Its emulsion droplet size and pharmacokinetics in rabbits were evaluated compared with sildenafil citrate-loaded commercial tablet. 


\section{Materials and methods}

\section{Materials}

Sildenafil base, sildenafil citrate and glyceryl monooleate were obtained from Hanmi Pharm. Co. (Hwasung, South Korea). Transcutol P was supplied by Gattefosse (Saint-Priest Cedex, France). Polysorbate 20 (Tween 20) and polyethylene glycol 4000 were purchased from Duksan Chemical Co. (Ansan, South Korea). Ethanol was of USP grade. The commercial product (Viagra ${ }^{\circledR}$; in a tablet form) was purchased from Pfizer Korea Pharm. Co. (Seoul, South Korea).

\section{Preparation of sildenafil lactate}

A Buchi 190 nozzle type mini spray dryer (Flawil, Switzerland) was used for the preparation of sildenafil lactate. Sildenafil base and lactic acid (1:1, molar ratio) were dissolved in ethanol and delivered to the nozzle $(0.7 \mathrm{~mm}$ diameter) at a flow rate of $5 \mathrm{~mL} / \mathrm{min}$ using a peristaltic pump, and spraydried at $100^{\circ} \mathrm{C}$ (inlet temperature) and $65-70^{\circ} \mathrm{C}$ outlet temperature. The pressure of spray air was $4 \mathrm{~kg} / \mathrm{cm}^{2}$. The flow rate of the drying air was maintained at the aspirator setting of 10 , which indicated the pressure of the aspirator filter vessel $(-25$ mbar). The direction of the air flow was the same as that of the sprayed products ( $\mathrm{Li}$ et al., 2008).

\section{Solubility}

An excess of sildenafil base, sildenafil citrate and sildenafil lactate (about $100 \mathrm{mg}$ ) was added to $10 \mathrm{~mL}$ solvents as shown in Table I. They were shaken in a water bath at $25^{\circ} \mathrm{C}$ for $24 \mathrm{~h}$, centrifuged at $3000 \mathrm{~g}$ for $10 \mathrm{~min}$ (Eppendorf, USA) and filtered through a membrane filter $(0.45 \mathrm{~mm})$ (Choi et al., 2008). The concentration of sildenafil in the resulting solution was analysed by HPLC as described below.

\section{Preparation of Sildenafil lactate-loaded SEDDS}

Sildenafil lactate $(0.3 \mathrm{~g})$ was dissolved in $4.7 \mathrm{~g}$ of the mixture of glyceryl monooleate /Transcutol/Tween 20 (3/0.5/1, g).

Table I. Solubility in various solvents

\begin{tabular}{lccc}
\hline \hline \multirow{2}{*}{ Solvent } & \multicolumn{3}{c}{ Solubility $(\mathrm{mg} / \mathrm{mL})$} \\
\cline { 2 - 4 } & $\begin{array}{c}\text { Sildenafil } \\
\text { base }\end{array}$ & $\begin{array}{c}\text { Sildenafil } \\
\text { citrate }\end{array}$ & $\begin{array}{c}\text { Sildenafil } \\
\text { lactate }\end{array}$ \\
\hline Distilled water & $0.0 \pm 0.0$ & $4.1 \pm 1.3$ & $92.5 \pm 10.5$ \\
Transcutol & $24.7 \pm 4.7$ & $3.4 \pm 0.7$ & $38.3 \pm 2.6$ \\
Glyceryl monooleate & $10.2 \pm 3.1$ & $2.5 \pm 0.4$ & $20.5 \pm 3.6$ \\
Tween 20 & $12.0 \pm 3.8$ & $5.6 \pm 0.9$ & $19.8 \pm 3.2$ \\
\hline
\end{tabular}

Each value represents the mean \pm S.D. $(n=3)$
The final mixture was vortexed until a clear solution was obtained. The final drug content of the liquid SEDDS was $6 \%$ $\mathrm{w} / \mathrm{w}$ ratio. The formulation was examined for signs of turbidity or phase separation.

Furthermore, the emulsion particle size of the emulsion was determined using a Zetasizer Nano ZS (Malvern Instruments, U.K.) dynamic light scattering particle size analyser at a wavelength of $635 \mathrm{~nm}$ and a scattering angle of $90^{\circ}$ at $25^{\circ} \mathrm{C}$. Liquid SEDDS were added to $25 \mathrm{~mL}$ of distilled water and shaken gently to form a fine emulsion and kept for $12 \mathrm{~h}$ at room temperature. All studies were repeated three times and the values of $z$-average diameters were used. The $z$-average diameter, also referred to as the harmonic intensity-weighted average hydrodynamic diameter, of each emulsion was derived from cumulated analysis by Automeasure software (Malvern Instruments, Malvern, UK).

\section{Pharmacokinetics}

Animals - all animal care and procedures were conducted according to the Guiding Principles in the Use of Animals in Toxicology, as adopted in 1989, revised in 1999 and amended in 2008 by the Society of Toxicology (SOT, 2008). Furthermore, the protocols for the animal studies were approved by the Institute of Laboratory Animal Resources of Yeungnam University. Twelve New Zealand albino male rabbits weighing 2.5-3.5 $\mathrm{kg}$ were fasted for $24 \mathrm{~h}$ prior to the experiments but allowed free access to water at a temperature of $20-24^{\circ} \mathrm{C}$ and a relative humidity $(\mathrm{RH})$ of $55 \pm 10 \%$ with a normal $12 \mathrm{~h} \mathrm{light/}$ dark cycle starting one week before the experiment.

Oral administration and blood collecting - Ten rabbits were divided into two groups. The sildenafil citrate-loaded conventional tablet was orally administered at the equivalent dose of $35 \mathrm{mg} / \mathrm{kg}$ sildenafil citrate $(25 \mathrm{mg} / \mathrm{kg}$ sildenafil $)$ in one group. The sildenafil lactate-loaded SEDDS was orally administered at the equivalent dose of $9.93 \mathrm{mg} / \mathrm{kg}$ sildenafil lactate $(8.33 \mathrm{mg} / \mathrm{kg}$ sildenafil). Then, $1 \mathrm{~mL}$ of blood samples were obtained at various intervals from the left or right ear vein into heparinised glass tubes, centrifuged at 3,000 $\mathrm{g}$ for $10 \mathrm{~min}$ using a $5415 \mathrm{C}$ centrifuge (Eppendorf, USA) and stored at $-70^{\circ} \mathrm{C}$ prior to analysis.

Blood sample analysis - Plasma $(0.1 \mathrm{~mL})$ was thoroughly mixed with $0.05 \mathrm{~mL} 0.1 \mathrm{~N}$ borax, $1 \mathrm{~mL}$ ether and $0.05 \mathrm{~mL}$ of acetonitrile solution containing nifedipine $(200 \mu \mathrm{g} / \mathrm{mL})$ as an internal standard. This mixture was vortexed for $2 \mathrm{~min}$ and centrifuged at $10,000 \mathrm{~g}$ for $10 \mathrm{~min}$ to precipitate the proteins. The supernatant layer $(0.5 \mathrm{~mL})$ was evaporated under $\mathrm{N}_{2}(\mathrm{~g})$. The residue was reconstituted in $50 \mu \mathrm{L}$ for the mobile phase. The resulting solution $(20 \mu \mathrm{L})$ was analysed by HPLC (Jasco 
UV-975, Japan) equipped with an Inertsil ODS-3 $\mathrm{C}_{18}$ column (GL science, $0.5 \mu \mathrm{m}, 25 \mathrm{~cm} \times 0.46 \mathrm{~cm}$ i.d.) and $\mathrm{UV}$ detector (Model L-7450). The mobile phase consisted of $20 \mathrm{mM}$ $\mathrm{KH}_{2} \mathrm{PO}_{4}$ and acetonitrile $(70: 30$, v/v). The eluent was monitored at $292 \mathrm{~nm}$ with a flow rate of $1.0 \mathrm{~mL} / \mathrm{min}$ (Gratz et al., 2004; Shin et al., 2006; Quintero et al., 2009).

\section{Result and Discussion}

Sildenafil lactate was prepared easily by spray-drying sildenafil base and lactic acid (1:1, molar ratio). The aqueous solubility of sildenafil base was about $14.5 \mu \mathrm{g} / \mathrm{mL}$, which indicated that this drug was poorly water-soluble (Elshafeey et al., 2009; Wang et al., 2008). As shown in Table I, the aqueous solubility of sildenafil salts was in the order of sildenafil base $<$ sildenafil citrate $<$ sildenafil lactate. In particular, the aqueous solubility of sildenafil lactate was about 25 -fold higher than sildenafil citrate, the commercial drug $(92.5 \pm 10.5$ vs. $4.1 \pm 1.3 \mathrm{mg} / \mathrm{mL}$ ). Compared with sildenafil base, sildenafil citrate reduced the drug solubility in other solvents such as glyceryl monooleate, Transcutol and Tween 20, but sildenafil lactate increased it further. Thus, sildenafil lactate was a salt form that provided an improved solubility of sildenafil (Jung et al., 2011). Furthermore, glyceryl monooleate, Transcutol and Tween 20 were selected as an oily vehicle, surfactant and cosurfactant, respectively, because they could solubilize sildenafil lactate and well mix together (Jung et al., 2011). In particular, the sildenafil lactate-loaded SEDDS composed of [sildenafil lactate/glyceryl monooleate/Transcutol/ Tween 20 $(3 / 30 / 5 / 10, \mathrm{~g})]$ showed no turbidity in water, $\mathrm{pH} 1.2, \mathrm{pH} 4.0$

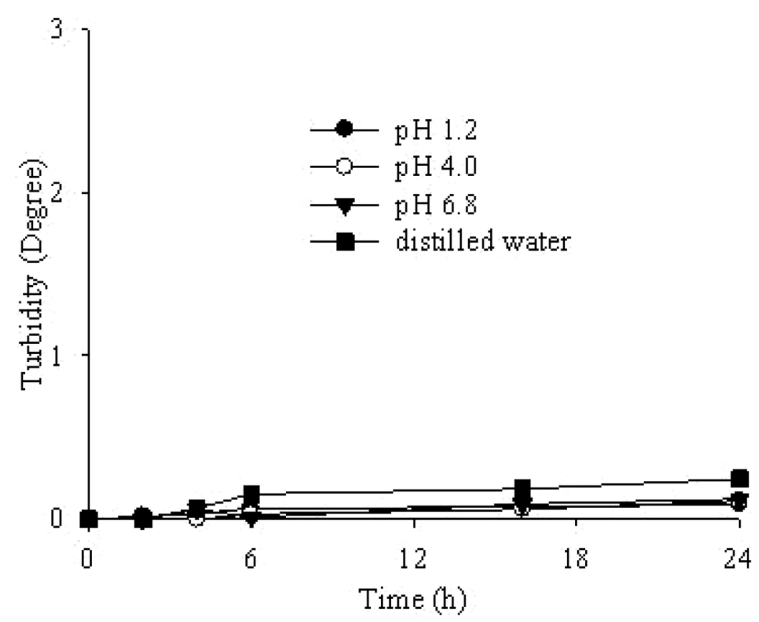

Figure 1. Turbidity of sildenafil lactate-loaded SEDDS in various solutions. Each value represents the mean \pm S.D $(n=3)$. The sildenafil lactate-loaded SEDDS was composed of [sildenafil lactate/glyceryl monooleate/Transcutol/ Tween $20(3 / 30 / 5 / 10, \mathrm{~g})]$. and $\mathrm{pH} 6.8$ solution for $24 \mathrm{~h}$ (Figure 1), and showed an emulsion droplet size of about $300 \mathrm{~nm}$ (Figure 2) (Balakrishnan et al., 2009). Thus, this SEDDS formulation was selected for pharmacokinetic study.

Figure 3 shows the change in mean plasma concentration of sildenafil after the oral administration of two sildenafil preparations at the different dose. The sildenafil citrate-loaded conventional tablet and sildenafil lactate-loaded SEDDS were orally administered at the equivalent dose of $35 \mathrm{mg} / \mathrm{kg}$ sildenafil citrate $(25 \mathrm{mg} / \mathrm{kg}$ sildenafil $)$ and $9.93 \mathrm{mg} / \mathrm{kg}$ sildenafil lactate $(8.33 \mathrm{mg} / \mathrm{kg}$ sildenafil; one-third drug dose compared to sildenafil citrate-loaded conventional tablet), respectively. To

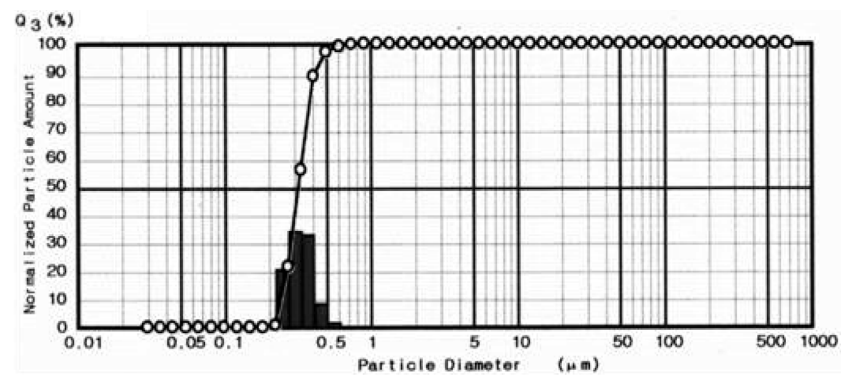

Figure 2. Emulsion droplet size of sildenafil lactate-loaded SEDDS in water. Each value represents the mean \pm S.D $(n=3)$. The sildenafil lactate-loaded SEDDS was composed of [sildenafil lactate /glyceryl monooleate/Transcutol/ Tween $20(3 / 30 / 5 / 10, \mathrm{~g})]$.

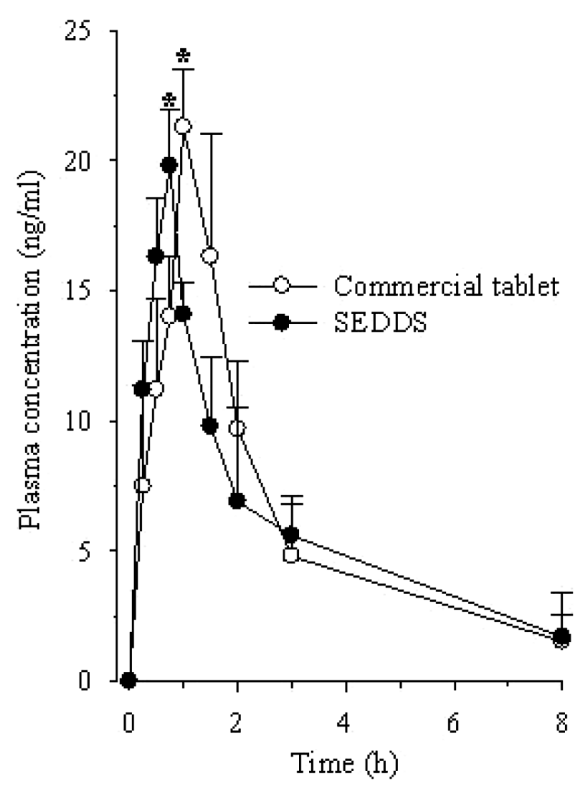

Figure 3. Plasma concentration-time profiles of the drug after the oral administration of the sildenafil citrate-loaded commercial tablet and sildenafil lactate-loaded SEDDS to rabbits. Each value represents the mean \pm S.D. $(\mathrm{n}=5)$. ${ }^{*} P<0.05$ compared with the sildenafil citrate-loaded commercial tablet. The sildenafil lactate-loaded SEDDS was composed of [sildenafil lactate /glyceryl monooleate/ Transcutol/ Tween 20 (3/30/5/10, g)]. 
Table II. Pharmacokinetic parameters

\begin{tabular}{lcc}
\hline \hline \multicolumn{1}{c}{ Parameters } & Commercial tablet & SEDDS \\
\hline AUC $(\mathrm{h} \cdot \mathrm{ng} / \mathrm{mL})$ & $35.97 \pm 6.61$ & $35.51 \pm 5.18$ \\
$\mathrm{~T}_{\max }(\mathrm{h})$ & $1.02 \pm 0.14$ & $0.58 \pm 0.12^{*}$ \\
$\mathrm{C}_{\max }(\mathrm{ng} / \mathrm{mL})$ & $18.69 \pm 2.58$ & $17.77 \pm 2.41$ \\
$\mathrm{t}_{1 / 2}(\mathrm{~h})$ & $1.43 \pm 0.48$ & $1.02 \pm .42$ \\
$\mathrm{~K}_{\mathrm{el}}\left(\mathrm{h}^{-1}\right)$ & $0.49 \pm 0.38$ & $1.68 \pm 0.62$ \\
\hline
\end{tabular}

Each value represents the mean \pm S.D. $(n=5)$.

$* P<0.05$ compared with the commercial tablet.

The sildenafil lactate-loaded SEDDS was composed of [sildenafil lactate/glyceryl monooleate /Transcutol/Tween 20 (3/30/5/10, g)].

$45 \mathrm{~min}$, the SEDDS gave higher initial plasma concentrations, followed by lower plasma concentrations compared with the commercial tablet. In particular, the initial plasma concentration of sildenafil from the SEDDS at 45 min was significantly higher than that of the commercial tablet $(P<0.05)$. In the self-emulsifying systems, the amount of free energy required to form an emulsion is very low, thereby allowing the spontaneous formation of an interface between oil droplets and the water (Balakrishnan et al., 2009). This suggests that the oil/ surfactant/co-surfactant and water phases effectively swell, decreasing the size of the oil droplets and eventually increasing the initial absorption.

The pharmacokinetic parameters are shown in Table II. The AUC, $\mathrm{C}_{\mathrm{max}}, \mathrm{K}_{\mathrm{el}}$ and $\mathrm{t}_{1 / 2}$ values of the solid SEDDS formulation were not significantly different from those of the commercial tablet in the rabbits. However, it gave significantly faster $T_{\max }$ than did the commercial tablet. In particular, the $T_{\max }$ value of the SEDDS was about 0.5 -fold lower than that of the commercial tablet (Jung et al., 2011). Thus, the sildenafil lactateloaded SEDDS at the one-third drug dose compared to sildenafil citrate-loaded conventional tablet might induce a fast onset of action and immediate erection without enhanced bioavailability compared with the sildenafil citrate-loaded commercial tablet.

\section{Conclusion}

The sildenafil lactate-loaded SEDDS composed of [sildenafil lactate/glyceryl monooleate /Transcutol/Tween 20 (3/30/ $5 / 10, \mathrm{~g})]$ showed an emulsion droplet size of about $300 \mathrm{~nm}$ and gave faster about 0.5 -fold $\mathrm{T}_{\max }$ than did the commercial tablet. Thus, the sildenafil lactate-loaded SEDDS at the one-third drug dose compared to sildenafil citrate-loaded conventional tablet might induce a fast onset of action and immediate erection without enhanced bioavailability compared with the sildenafil citrate-loaded commercial tablet.

\section{Acknowledgements}

This research was supported by the Yeungnam University research grants in 2010 .

\section{References}

Amidon, G.L., Lennernas, H., Shah, V.P., Crison, J.R., 1995. A theoretical basis for a biopharmaceutics drug classification : the correlation of in vitro drug product dissolution and in vivo bioavailability. Pharm. Res. 12, 413-420.

Balakrishnan, P., Lee, B.J., Oh, D.H., Kim, J.O., Lee, Y.I., Kim, D.D., Jee, J.P., Lee, Y.B., Woo, J.S., Yong, C.S., Choi, H.G., 2009. Enhanced oral bioavailability of Coenzyme $\mathrm{Q}_{10}$ by selfemulsifying drug delivery systems. Int. J. Pharm. 374, 66-72.

Boolell, M., Gepi-Attee, S., Gingell, J.C., Allen, M.J., 1996. Sildenafil, a novel effective oral therapy for male erectile dysfunction. Br. J. Urol. 184, 63-72.

Choi, H.G., Oh, Y.K., Kim, C.K., 1998. In-situ gelling and mucoadhesive liquid suppository containing acetaminophen: enhanced bioavailability. Int. J. Pharm. 165, 23-32.

Eardly, I., Ellis, P., Boolell, M., Wulff, M., 2002. Onset and duration of action of sildenafil citrate treatment of erectile dysfunction. Br. J. Clin. Pharmacol. 53, 61S-65S.

Elshafeey, A.H., Bendas, E.R., Mohamed, O.H., 2009. Intranasal microemulsion of sildenafil citrate: in vitro evaluation and in vivo pharmacokinetic study in rabbits. AAPS PharmSciTech. 10(2), 361-367.

Gratz, S.R., Flurer, C.L., Wolnik, K.A., 2004. Analysis of undeclared synthetic phosphodiesterase-5 inhibitors in dietary supplements and herbal matrices by LC-ESI-MS and LC-UV. J. Pharm. Biomed. Anal. 36(3), 525-533.

Jung, S.J., Seo, Y.G., Kim, G.K., Woo, J.S., Yong, C.S., Choi, H.G., 2011. Comparison of the solubility and pharmacokinetics of sildenafil salts, Arch. Pharm. Res. 34(3) 451-454.

Li, D.X., Han, M.J., Balakrishnan, P., Yan, Y.D., Oh, D.H., Joe, J.H., Seo, Y.G., Kim, J.O., Park, S.M., Yong, C.S., Choi, H.G., 2010. Enhanced oral bioavailability of flurbiprofen by combined use of micelle solution and inclusion compound. Arch. Pharm. Res. 33, 95-101.

Nichols, D.J., Muirhead, G.J., Harness, J.A., 2002. Pharmacokinetics of sildenafil after single oral doses in healthy male subjects: absolute bioavailability, food effects and dose proportionality. Br. J. Clin. Pharmacol. 53 (Suppl 1), 5S-12S.

Quintero, A., Caldera, A., Milano, B., Odreman, I., Hurtado, A., Manzanares, L., Villamizar, J., 2009. Validation of an HPLC method for sildenafil citrate analysis in human plasma samples. Pharmazie 64(12), 796-799.

Shah, N.H., Carvajal, M.T., Patel, C.I., Infeld, M.H., Malick, A.W., 1994. Self-emulsifying drug delivery systems (SEDDS) with polyglycolyzed glycerides for improving in vitro dissolution and oral absorption of lipophilic drugs. Int. J. Pharm. 106, 1523. 
Shin, H.S., Bae, S.K., Lee, M.G., 2006. Pharmacokinetics of sildenafil after intravenous and oral administration in rats: Hepatic and intestinal first-pass effects. Int. J. Pharm. 320, 6470.

Society of Toxicology (SOT), 2008. Guiding Principles in the Use of Animals in Toxicology. www.toxicology.org/AI/FA/guid- ingprinciples.pdf.

Wang, Y., Chow, M.S., Zuo, Z., 2008. Mechanistic analysis of pHdependent solubility and trans-membrane permeability of amphoteric compounds: application to sildenafil. Int. J. Pharm. $352,217-224$. 